\title{
Research on Collection Resource Construction of Applied Universities Based on Circulation Data Analysis
}

\author{
Jingping Zhao \\ Library of Xi'an University, Xi'an, 710065, China
}

\begin{abstract}
Whether the collection resources can meet the requirements of subject construction is an important index to judge whether the university library collection is reasonable or not. Based on the analysis of Xi'an University of library, including the collection resource structure, the books borrowing ratio and the books collection time, this paper puts forward some countermeasures to optimize the collection resource structure and promote the old-removing system to provide some references for the library collection resourcesconstruction of the applied universities.
\end{abstract}

Keywords:collection resource construction, circulation data, applied universities

\section{Introduction}

As the main hardware of the applied university, the university library is the information service centre of the university, and is also an indispensable external condition for the growth of the university students. With the continuous expansion of the scale of higher education and training constantly adjust and constantly improve the level of discipline structure, and deal with high market price, the library how to tap the existing literature potential, improve utilization rate and the circulation of books of literature, in order to alleviate the contradiction between supply and demand in the mouth before borrowing books, has become a an important issue of common concern to the University library. If the university library carried out regular analysis on collection book structure and quality through effective means, carries on the statistics to use, not only can achieve the quality of the purchasing and inspection documents, but also can provide a reliable scientific basis for the development of library collection replenishment plan, purchasing strategy, make the limited funds to buy books reasonably use. The collection resources of the modern library include two parts, printed and digital resources. Reasonable collection structure can improve the quality of the collection of books, select books for readers, practice the service of readers, and reduce the work burden of librarians. Therefore, the construction of the library collection is still one of the important contents of the library. After the computer system is involved in the management of books, the circulation data 
objectively and truly records the usage of the collection printing resources, including the circulation times of books and the history of reading. At the same time, the cycle of books and the borrowing rate of literature can also be used to effectively plan the structure of library books. We can build the collection resources based on the circulation data.

\section{Circulation Data Analysis}

We analyze the circulation data analysis of the library of Xi'an University in 2015. The data of structure of collection resource, books borrowing ratio and books collection time is shown in Table 1, Table 2 and Table 3.

\subsection{Ccollection resource structure}

Table 1: Collection resource structure ofXi'an University

\begin{tabular}{|l|r|l|r|}
\hline \multirow{2}{*}{ category } & $\begin{array}{l}\text { number of } \\
\text { total } \\
\text { collections }\end{array}$ & $\begin{array}{l}\text { number of } \\
\text { collections before } \\
\text { 2006 }\end{array}$ & $\begin{array}{l}\text { lorrowing } \\
\text { ratio }\end{array}$ \\
\hline A & 523 & 75 & $14.3 \%$ \\
\hline B & 8003 & 312 & $3.9 \%$ \\
\hline C & 2301 & 435 & $18.9 \%$ \\
\hline D & 5002 & 263 & $5.3 \%$ \\
\hline E & 6243 & 322 & $5.2 \%$ \\
\hline F & 9287 & 450 & $4.8 \%$ \\
\hline G & 7847 & 357 & $4.5 \%$ \\
\hline H & 6779 & 166 & $2.4 \%$ \\
\hline I & 10485 & 289 & $2.8 \%$ \\
\hline J & 2480 & 131 & $5.3 \%$ \\
\hline K & 8924 & 53 & $0.6 \%$ \\
\hline L & 9371 & 484 & $5.2 \%$ \\
\hline N & 886 & 249 & $28.1 \%$ \\
\hline O & 6682 & 427 & $6.4 \%$ \\
\hline P & 6933 & 255 & $3.7 \%$ \\
\hline Q & 6565 & 304 & $4.6 \%$ \\
\hline R & 995 & 410 & $41.2 \%$ \\
\hline S & 169 & 57 & $33.7 \%$ \\
\hline Others & 1396 & 20 & $1.4 \%$ \\
\hline & & & \\
\hline
\end{tabular}




\subsection{Books borrowing ratio}

Table 2: Books borrowing ratio ofXi' an University

\begin{tabular}{|l|r|l|r|}
\hline category & $\begin{array}{l}\text { number of } \\
\text { collections }\end{array}$ & $\begin{array}{l}\text { number of } \\
\text { borrowing }\end{array}$ & borrowing ratio \\
\hline A & 523 & 35 & $6.7 \%$ \\
\hline B & 8003 & 326 & $4.1 \%$ \\
\hline C & 2301 & 293 & $12.7 \%$ \\
\hline D & 5002 & 139 & $2.8 \%$ \\
\hline E & 6243 & 421 & $6.7 \%$ \\
\hline F & 9287 & 320 & $3.4 \%$ \\
\hline G & 7847 & 136 & $1.7 \%$ \\
\hline H & 6779 & 368 & $5.4 \%$ \\
\hline I & 10485 & 1362 & $13.0 \%$ \\
\hline J & 2480 & 39 & $1.6 \%$ \\
\hline K & 8924 & 69 & $0.8 \%$ \\
\hline L & 9371 & 362 & $3.9 \%$ \\
\hline N & 886 & 196 & $22.1 \%$ \\
\hline O & 6682 & 416 & $6.2 \%$ \\
\hline P & 6933 & 341 & $4.9 \%$ \\
\hline Q & 6565 & 536 & $8.2 \%$ \\
\hline R & 995 & 23 & $2.3 \%$ \\
\hline S & 169 & 59 & $34.9 \%$ \\
\hline Others & 1396 & 15 & $1.1 \%$ \\
\hline & & & \\
\hline
\end{tabular}

\subsection{Books collection time}

Table 3: Books collection time ofXi'an University

\begin{tabular}{|l|r|l|r|}
\hline category & $\begin{array}{l}\text { number of } \\
\text { total } \\
\text { collections }\end{array}$ & $\begin{array}{l}\text { number of } \\
\text { collections before } \\
\text { 2006 }\end{array}$ & $\begin{array}{l}\text { ratio of } \\
\text { collections } \\
\text { before 2006 }\end{array}$ \\
\hline A & 523 & 75 & $14.3 \%$ \\
\hline B & 8003 & 312 & $3.9 \%$ \\
\hline C & 2301 & 435 & $18.9 \%$ \\
\hline D & 5002 & 263 & $5.3 \%$ \\
\hline E & 6243 & 322 & $5.2 \%$ \\
\hline F & 9287 & 450 & $4.8 \%$ \\
\hline G & 7847 & 357 & $4.5 \%$ \\
\hline H & 6779 & 166 & $2.4 \%$ \\
\hline I & 10485 & 289 & $2.8 \%$ \\
\hline J & 2480 & 131 & $5.3 \%$ \\
\hline K & 8924 & 53 & $0.6 \%$ \\
\hline L & 9371 & 484 & $5.2 \%$ \\
\hline
\end{tabular}




\begin{tabular}{|l|r|r|r|}
$\mathrm{N}$ & 886 & 249 & $28.1 \%$ \\
\hline $\mathrm{O}$ & 6682 & 427 & $6.4 \%$ \\
\hline $\mathrm{P}$ & 6933 & 255 & $3.7 \%$ \\
\hline $\mathrm{Q}$ & 6565 & 304 & $4.6 \%$ \\
\hline $\mathrm{R}$ & 995 & 410 & $41.2 \%$ \\
\hline $\mathrm{S}$ & 169 & 57 & $33.7 \%$ \\
\hline Others & 1396 & 20 & $1.4 \%$ \\
\hline
\end{tabular}

\section{Suggestions of collection resource construction based on circulation data analysis}

\subsection{Optimize resource structure}

The literature purchasing strategy in the application oriented universitiesshould be adjusted for possible on-demand procurement, in order to meet the growing information needs of teachers and students. At the same time, we can learn from other colleges to edit and purchase before borrowing. Both of them can guarantee the purchase of books meet the readers' needs, but also can greatly improve the utilization of literature. The construction of literature resources is a long-term system engineering, management personnel need rationality of the structure of library collection adjust procurement plan according to the statistical data generated in work, the only way to better meet the needs of school reform and development of the school, meet the needs of teaching and research in order to provide better service for reader. The construction of the library of Xi'an University in the past thirteen years and the initial formation of the collection system, collection can meet the basic needs of readers, but the collection structure needs to be further improved. We should ensure the basic needs of the readersandstrengthen the purchase the books of emerging professional and key scientific research project.

\subsection{Promote old-removing system}

Statistical results show that it is an indisputable fact that the collection of books published more than 10 years ago has a low borrowing rate. Therefore, the establishment of book weeding system to reduce labor costs and improve utilization of book value is an inevitable choice. This is also the fundamental guarantee to improve the vitality of the collection. In accordance with the relevant literature metrology research results, the half-life of literature aging is generally between 6 years, domestic and foreign academics generally believe that the effective use of books in about 10 years. The half-life of literature aging depends on many factors, including the content and nature of the subject, the change of the times, the need of human culture, the development of science and technology, the social environment and so on. For example, the basic theory of the subject more stable than the half-life of literature usually application subject long; long history literature may be better than new chief education half-life. For books of the same age, the rate of use may vary very far. Therefore, in the book 
the old tick absolutely can not only make the decision to eliminate old books, but should consider other factors, such as content, usage, carefully sorting and weeding work. For some early publication, with the value of cultural relics and rare books of ancient literature, we should give the corresponding protection.

\section{Conclusion}

The circulation data is objective and effective. We can make use of it to accurately find the books which are in accordance with the checking conditions by inputting relevant filtering conditions, saving a lot of time and effort. The scientific analysis of the circulation data can show the reader's use situation and the collection resource situation. Based on the analysis, we can take effective measures to adjust the procurement plan to ensure the quality of the collection resource.

\section{References}

[1]Yuan Hongzhi, OnLibraryStructureandReadersTendencyfromthePerspective ofBookCirculationData-Taking theLibraryofHengyangNormalUniversityas anExample, Journal of Hengyang Normal University, 37 (2), pp. 170-173, 2016.

[2] Ma Lei, Research on Collection Resource Construction of University Library Based on Analysis of Circulation data-A case of Chinese Books in Wuhan Campus Library of Yangtze University, Journal of Library and Information Sciences in Agriculture, 28(11), pp. 37-41, 2016.

[3]Liu Bo, On Library Preservation Resource Construction Based on the Circulation Data: Taking Liaoning Shihua University as an Example, Contemporary Library, 45(1), 46-48, 2016.

[4] Jiang Lihu, Zhu Lihong, Song Jing, Liu Lifang, Theanalysisofcirculationdataofnewbooks andtheresearchonconstructionofsubjectcollectiontheLibraryofAgriculturalUniversityofHebei,

JournalofAgriculturalUniversityofHebei (Agriculture\&ForestryEducationEditon), 13(4), pp. 512-515, 2011. 